\title{
EL RAPTO DE FRANCISCO AYALA Y SUS TRASVASES LITERARIOS
}

\author{
Sandra Mendoza Vera \\ Universidad de Murcia \\ sandra.mendoza@um.es
}

Resumen: Este artículo analiza la historia editorial vivida por El rapto, novela corta de Francisco Ayala que, desde que se publicó en España en 1965 de forma independiente, ha aparecido reunida junto a otras novelas cortas y cuentos en diferentes recopilaciones. Además de trazar sus trasvases literarios, analizaremos qué tipo de volumen es De raptos, violaciones y otras inconveniencias, primera recopilación en que se incluyó esta obra ayaliana, y elaboraremos una breve comparación entre esta novela corta y los cuentos aquí reunidos para poner de relieve los aspectos que tienen en común.

Palabras clave: El rapto, Francisco Ayala, historia editorial, novela corta, recopilación.

\section{FRANCISCO AYALA'S EL RAPTO AND ITS LITERARY TRANSFERS}

\begin{abstract}
This article analyzes the editorial history lived by El rapto, Francisco Ayala's nouvelle which, since it was published in Spain in 1965 independently, has appeared assembled with other nouvelles and short stories in different compilations. In addition to tracing these literary transfers, we will analyze what kind of volume is De raptos, violaciones $y$ otras inconveniencias, the first compilation in which this Ayalian work was included, and we will elaborate a brief comparison between this nouvelle and the short stories gathered here to emphasize the aspects they have in common.
\end{abstract}

Keywords: El rapto, Francisco Ayala, editorial history, nouvelle, compilation.

DOI: https://doi.org/10.24029/lejana.2020.13.430

Recibido: el 24 de noviembre de 2018

Aceptado: el 1 de marzo de 2019

Publicado: el 19 de febrero de 2020 


\section{Introducción ${ }^{1}$}

El rapto, novela corta de Francisco Ayala, apareció publicada suelta por primera vez en 1965 en España, cuando el autor aún se encontraba exiliado, en la colección La Novela Popular Española. Desde esta fecha y hasta hoy, esta novelita no solo se ha reeditado como obra independiente, sino que también ha aparecido reunida junto a otras narraciones en diferentes recopilaciones, preparadas por el propio Ayala o bien por otros editores. Tal trasvase editorial, que puede considerarse explicación (o consecuencia) de los numerosos estudios de que tal obra ha sido objeto, no es insólito en la obra literaria (y ensayística) ayaliana. Carolyn Richmond afirma que dichos traslados de textos de unas obras a otras son un procedimiento sintomático del universo creativo del escritor granadino, del cual hará uso para (re)componer obras que giran en torno a un tema común: "a episodios de la historia de España en Los usurpadores; a historias en torno a la guerra civil en La cabeza del codero; a anécdotas de tipo familiar en Historias de macacos (1955); a noticias diversas e incompletas en las dos novelas del Caribe; a un clásico de la literatura en El rapto (1965)" (2011: 18). Esta reunión y combinación de narraciones cortas en una recopilación posterior puede dar lugar a una obra unitaria y fragmentaria a la vez, en definitiva, una obra nueva según esta experta en la obra ayaliana.

Este perfil de Ayala como recopilador de narrativa breve ha sido objeto de menor atención en la abundante bibliografía existente en torno a su obra. Asimismo, el campo investigador hispánico adolece de la falta de estudios sobre la recopilación de relatos breves como modelo textual, frente a los campos filológicos francófono y anglosajón, en los que críticos como Langlet e Ingram han dedicado varios estudios a los denominados recueil y short story cycle, modelo este último surgido en el siglo XX vinculado a la recopilación de relatos.

Por ello, en este estudio proponemos adentrarnos en la historia editorial vivida por $E l$ rapto, dado que este tipo de enfoque más sociológico y pragmático es conveniente para el estudio de una novela corta, género cuya publicación y pervivencia suelen estar estrechamente vinculadas a su aparición en una revista o colección. En este sentido, seguimos los postulados de Manuel Martínez Arnaldos, quien afirma sobre este género narrativo que "para analizar su contenido o naturaleza debemos examinar, paralela o tangencialmente, la función del tipo de marco o contexto que la determina (y no únicamente en el que se desarrolla)" (1996: 48), aunque ello no implica que su contenido y naturaleza dependa enteramente del tipo de colección o revista que la albergue.

La historia editorial de El rapto que vamos a trazar irá acompañada de un análisis de índole más teórico y comparativo al estudiar, por un lado, qué tipo de recopilación o colección es De raptos, violaciones y otras inconveniencias (1966), volumen en que apareció esta novela corta ayaliana por primera vez tras ser publicada como novela corta independiente, $y$, por otro lado, el resto de textos reunidos en esta misma obra, elaborando, así, una aproximación comparativa entre los mismos.

\footnotetext{
${ }^{1}$ Esta investigación ha sido realizada con el apoyo de una beca para la formación de profesorado universitario del Ministerio de Ciencia, Innovación y Universidades (FPU17/00092).
} 


\section{Recorrido trazado por $E l$ rapto en sus trasvases literarios}

Es de necesaria mención la Fundación Francisco Ayala, en cuya página web se pueden hallar las distintas publicaciones y reediciones que han tenido todos los textos ayalianos, lo cual ha facilitado nuestra labor de rastreo del camino labrado por El rapto, desde que viera la luz en España en 1965. No era esta la primera vez que Ayala publicaba en España desde el exilio, pues en 1955 en Madrid ya había aparecido la colección Historia de macacos, cuando el autor se encontraba en Puerto Rico. En su primera publicación El rapto apareció como una novela corta independiente en el primer número de la colección La Novela Popular. Contemporánea, inédita, española, dirigida por Jorge Cela Trulock, con cuyo hermano, Camilo José, se había estado carteando Ayala con motivo de la preparación de esta obra. Al leer estas cartasdisponibles en la página web de la Fundación Francisco Ayala - se descubre que El rapto fue una obra encargada por Camilo José Cela, quien además sugirió el cambio del título de esta novela corta, previamente titulada Vicente de la Roca. El hecho de que tal composición sirviera para inaugurar esta colección adquiere especial relevancia para Pujante Segura (2018), si bien su singularidad va más allá. Numerosos relatos breves ayalianos fueron publicados primero en revistas o en prensa para después reunirse y combinarse con otras narraciones en una misma recopilación; no obstante, solo El rapto y El Hechizado ${ }^{2} \mathrm{se}$ publicaron como un libro independiente antes de aparecer recopilados con otros textos en una colección posterior. El hecho de que del amplio universo literario ayaliano únicamente estas dos piezas de narrativa breve se hayan publicado originalmente como obras autónomas nos parece especialmente significativo.

La editorial Alfaguara en 1966, solo un año después, publicó De raptos, violaciones y otras inconveniencias, cuyo título hace referencia a dos de las narraciones que incluye, $E l$ rapto y "Violación en California"; el término "inconveniencias" abarca las otras tres narraciones reunidas: "El as de Bastos", "Una boda sonada" y "Un pez". Estas y "Violación en California" ya habían sido recopiladas previamente en la colección El as de Bastos, que apareció en la editorial Sur de Buenos Aires en 1963. Cabe destacar que "Violación en California" y "Una boda sonada", antes de ser incluidas en este último volumen, aparecieron en las revistas Cuadernos Americanos (1961, vol. Xx, $\mathrm{n}^{\circ}$ 3) y Papeles de Son Armadans (1962, vol. XXIV, núm. LXXII), respectivamente. Otras tres narraciones componían El as de Bastos: "Baile de máscaras", "El prodigio" y "El inquisidor". Estas dos últimas se reeditaron en otras recopilaciones, pero Ayala decidió no incluirlas, como tampoco hizo con "Baile de máscaras", en De raptos, violaciones y otras inconveniencias. Cabe señalar que Ayala, como escritor, estaba siempre muy pendiente de los avatares editoriales; así, en su artículo "Nueva divagación de la novela" menciona que "por incitación de Camilo José Cela, redacté con destino a una serie popular lanzada por las Ediciones Alfaguara una novelita, El rapto (que la misma casa acaba de reeditar, junto con otras anteriores mías, en un tomo titulado De raptos, violaciones y otras inconveniencias)" (2007a [1967]: 176-177).

En 1982 la editorial Seix Barral publicó De raptos, violaciones, macacos y demás inconveniencias, cuyo título responde al hecho de que, además de todas las narraciones de la colección anterior, se recopilaron los seis relatos que conformaban Historia de macacos: el

\footnotetext{
${ }^{2}$ El número 8 de la colección Cuadernos de la Quimera (editorial Emecé) publicado en Buenos Aires en 1944 contenía esta obrita que fue reseñada ese mismo año por Jorge Luis Borges.
} 
que da título a esta recopilación, "La barba del capitán", "Encuentro", "The Last Supper", "Un cuento de Maupassant” y "El colega desconocido". Seis años más tarde, la editorial madrileña Montena prepara la colección El jardín de las malicias ${ }^{3}$, donde se reúnen junto a $E l$ rapto relatos procedentes de la recopilación De triunfos y penas y otros publicados primeramente en prensa o revistas literarias.

El rapto se establecerá como título para la colección publicada por Alfaguara en 1993, con prólogo de Luis García Montero y una reflexión de Ayala sobre el género del cuento en la contraportada:

En cierto modo, todo cuento es a twice-told tale, y varios de los que componen este volumen - empezando por "El rapto", que le da título- son cuentos contados ya de antes: éste en particular, nada menos que por Cervantes. Pero ello nada dice de su novedad. El cuento de nunca acabar que es la vida repite las mismas situaciones siempre de nuevo, es cierto; pero cada cual las vive a su manera. Y así, esta colección de relatos míos refleja mi propia imagen del mundo, que podrá ser amarga a veces, pero que en definitiva suele ser bastante divertida. (1993)

De mayor extensión que las anteriores, esta recopilación incluye un total de veintisiete relatos. Llama la atención que el prólogo que acompañaba a El rapto-que encabeza ahora este volumen - no se haya incorporado. Todos los textos proceden de la prensa, revistas y recopilaciones, en concreto El as de Bastos, Historia de macacos y De triunfos y penas, excepto "No me quieras tanto", que es el único relato inédito. Ello destaca, además, porque las colecciones de la etapa de madurez de Ayala que estamos analizando recopilan, en general, textos que ya habían sido publicados con anterioridad.

También Alianza en 2001 publicó una colección extensa, La niña de oro y otros relatos, que en el volumen I de las Obras completas: Narrativa editado por Carolyn Richmond en 2012 aparece dividida en dos partes: "«El prodigio» y otras invenciones", con relatos procedentes, en su mayoría, de El as de Bastos y De triunfos y penas, y "«Dulces recuerdos» y otras ficciones", que proceden de las mismas colecciones mencionadas y de $E l$ jardín de las malicias. En esta segunda parte, Richmond incluye El rapto junto a "Dulces recuerdos", "Una boda sonada", "El as de Bastos", "Violación en California", "El camino de nuestra vida", "Una Nochebuena en tierra de infieles, o Son como niños" y "Glorioso triunfo del príncipe Arjuna". Aparece encabezando esta obra "Y va de cuento", un texto cuyo origen ha de ser buscado en una colección ayaliana de índole ensayística, El tiempo y yo o el mundo a la espalda (1992).

Sin contar esta última obra, las recopilaciones hasta aquí reseñadas fueron preparadas por el propio Ayala. El rapto fue también reeditado como obra individual hasta en dos ocasiones por parte de otros editores, como Phyllis Zatling Boring, que preparó una edición bilingüe en inglés y español en 1971 en la editorial de Nueva York Harcourt Brace Jovanovich y la Junta de Andalucía, que preparó en 2016 una versión que incluía el capítulo LI de la primera parte del Quijote, donde se halla el relato narrado por el cabrero Eugenio que reelabora Ayala en su novela corta. Cabe destacar la colección —que podríamos denominar

\footnotetext{
${ }^{3}$ En clara alusión a la obra ayaliana El jardín de las delicias.

${ }^{4}$ Destaca aquí la inclusión de El rapto dentro del género cuento, cuando el propio Ayala - y numerosos críticos - en otras ocasiones se ha referido a esta obra como novela corta. Tal oscilación terminológica acompaña siempre a este género.
} 
exógena- editada por la estudiosa de la obra ayaliana Estelle Irizarry en 1974 (Barcelona, Labor), cuyo título alude a las tres narraciones que reúne: El rapto; Fragancia de jazmines; Diálogo entre el amor y un viejo.

\section{De raptos, violaciones y otras inconveniencias, una recopilación cohesionada}

Si entendemos la creación de recopilaciones de relatos breves como modelo textual, podemos señalar el inicio de tal macrogénero en la Edad Media de mano de Boccaccio con el Decamerón y su continuación más reseñable con las Novelas ejemplares de Cervantes. Tras el cultivo prolífico de este tipo de recopilaciones en el siglo XVII y su prolongación dieciochesca, llegamos a la gran eclosión narrativa del siglo XIX - en la que la prensa fue un vehículo de difusión esencial- Será en el siglo XX cuando el manejo de este género sea destacado por numerosos críticos, pues será en esta época cuando surja, para algunos estudiosos, un nuevo modelo vinculado a la recopilación de relatos, el denominado short story cycle por Ingram (1971), que algunos críticos han traducido como "cuentos integrados" (Gabriel Matelo, 2010), “colecciones de relatos integrados" (José Sánchez Carbó, 2012) o“cuentarios" (Francisca Noguerol, 2008 y Bénédicte Vauthier, 2017), destacando así su naturaleza integradora y unitaria, ya defendida por Ingram, cuya obra Representative Short Story Cycle of the Twentieth Century ha sido considerada pionera por los estudiosos de este género.

Ingram definió el short story cycle como "a book of short stories so linked to each other by their author that the reader's successive experience on various levels of the pattern of the whole significantly modifies his experience of each of its component parts" (1971: 19). Tal definición pionera y canónica pone de relieve la simultánea autonomía e interdependencia de los textos que componen el ciclo. Dada la conexión entre las distintas partes que conforman el todo, Ingram (1971) distinguió el short story cycle de una simple colección de historias independientes y clasificó el primero en tres tipos: composed cycle, el que el autor concibe como un todo antes de escribir las distintas narraciones; arranged cycle, que consiste en "stories which an author or editor-author has brought together to illuminate or comment upon one another by juxtaposition or association" (1971: 18); y completed cycle, que es un conjunto de "linked stories which are neither strictly composed nor merely arranged. They may have begun as independent dissociated stories. But soon their author became conscious of unifying strands" (1971: 18).

Los distintos elementos unificadores que pueden conformar un short story cycle son, para Ingram, el tema, los personajes, el tiempo, el espacio, el prólogo y el epílogo. Para el caso de Ayala, Ana Rueda (1995) señaló que La cabeza del cordero responde a un patrón clásico de ciclo de cuentos al integrarlos Ayala bajo una temática común: la guerra civil española. No obstante, De raptos, violaciones y otras inconveniencias no podría ser definida como un ciclo de relatos integrados, pues en esta recopilación Ayala incluyó narraciones que fueron compuestas - y publicadas - de manera individual y separada, si bien más adelante las unió "con un hilo tan sutil que parece que las articula en función de un concepto general" (Vauthier, 2017: 42), es decir, que Ayala integró El rapto y las otras narraciones procedentes de El as de Bastos "en una unidad superior pero no orgánica" (Matelo, 2010: 2210). Sí podríamos clasificar tal colección ayaliana bajo el tipo completed cycle, dado que cumple el 
requisito marcado por Ingram de, a pesar de ser sus narraciones historias concebidas independientemente, mostrar cierta unidad, como veremos al comparar estas últimas.

Se han de mencionar las críticas recibidas por Ingram, quien no tuvo en cuenta la importancia que puede llegar a adquirir la labor de un editor en la construcción de tales obras recopilatorias. Esta figura resulta clave para Vauthier (2017), pues el editor puede ser quien sugiera la reedición unitaria de relatos publicados previamente. Recordemos que Camilo José Cela no solo alentó a Ayala para que redactara El rapto, sino que también le propuso este título, que fue el definitivo. Otros críticos han ampliado la teoría de Ingram aportando comentarios a su definición del short story cycle o nuevas clasificaciones de los ciclos, recopilaciones y colecciones. Así, Gabriela Mora (1993) propone distinguir entre la colección de cuentos integrada, cuya característica más resaltable es su efecto unificador, y una colección de cuentos miscelánea, en la que no existe - aparentemente - relación entre las narraciones que lo componen, por lo que el efecto que produce es de separación. A este último caso responde De raptos, violaciones y otras inconveniencias, pues su unidad se fragmenta al poder leerse y comprenderse las distintas narraciones por separado; estas incluso se pueden leer en un orden distinto al que aparecen en el volumen. En este sentido, cabe recordar que, para esta última crítica, los ciclos de cuentos "necesitan la lectura de todos los relatos, [pero] no todos [...] exigen la sucesiva para captar mejor el sentido de la colección" (Mora, 1993: 135).

Francisca Noguerol, por su parte, ofrece una clasificación de distintos tipos de ciclos: los cuentarios modernos, que "presentan unidad espacial, temática y de personajes para ofrecer una visión totalizadora de la realidad" (2008: 165) y que reúnen, por tanto, textos unidos por el espacio, la historia o los personajes; y los cuentarios posmodernos, surgidos en los albores del siglo XX bajo el espíritu de las vanguardias, que albergan textos unidos por un motivo o por su adscripción genérica. Como De raptos, violaciones y otras inconveniencias presenta variedad genérica (cuento y novela corta), no podemos clasificarla como un cuentario posmoderno que recopile textos que responden a la misma adscripción genérica, pero sí podríamos definirla como cuentario cuyos textos se relacionan por un motivo común, ya explícito desde el título.

El campo filológico francés ofrece aportaciones muy interesantes en torno a este género narrativo. La collection es un fenómeno editorial para Christine Rivalan y Miriam Nicoli (2014), quienes ponen de relieve la importancia no solo del proceso de creación literaria realizado por el escritor, sino también del proceso de difusión, del que se encargan el autor, el editor, el librero y otros mediadores, y del proceso de recepción, donde entran en juego los lectores. Irène Langlet habla del recueil como "puzzle ou série, cycle ou mélange" (2003: 11)y detalla los distintos criterios que pueden sustentar la recopilación de textos: "homogénéité/hétérogénéité, cohérence/discohérence, ordre/désordre" (2003: 12), si bien ella se basa en tres criterios para clasificar los distintos tipos de recueils: según el género al que se adscriben los textos recopilados, con especial preponderancia del ensayo, la poesía y la nouvelle, género este último que "apparaît dès ses débuts comme une forme en recueil" (2003: 12); según la forma o estructura, si los textos están reunidos con un marco o no, si tienden a la unidad o al fragmentarismo, si son coherentes o si por el contrario tienen diferente naturaleza genérica; por último, según la autoría, los recueils pueden ser póstumos o no, según se publiquen tras la muerte o en vida del autor, autographes o allographes en función 
de si responden a una intención determinada o están torpemente realizados, y del mismo autor o del mismo editor. Siguiendo esta clasificación, podemos definir De raptos, violaciones y otras inconveniencias como un recueil de novela corta y cuento, según el género recopilado; carente de marco, pero hasta cierto punto unitario gracias al prólogo que la encabeza desde el punto de vista de la estructura; y, según el actor o autor de la obra, no póstumo y preparado por el propio Ayala con asesoramiento editorial por parte de los hermanos Cela con fines económicos y comerciales, pero también personales y literarios.

Podemos entonces afirmar que esta obra ayaliana no es un ciclo de relatos integrados, según la definición tradicional de Ingram, sino una recopilación de relatos independientes que, pese a haber sido publicados anteriormente de forma separada, muestran ciertos puntos de conexión. No obstante, las distintas adscripciones que hemos ofrecido acerca de esta obra a las tipologías señaladas responde a una intención meramente descriptiva; estos subgéneros no son compartimentos estancos, de hecho, "una misma colección puede caber en dos o más casilleros" (Mora, 1993: 136). Tales clasificaciones enlazan, a su vez, con el análisis comparativo sobre las distintas narraciones recopiladas en esta obra, el cual nos permitirá hallar esos puntos en común que dan cohesión y unidad a la recopilación.

\section{Análisis comparativo de los relatos de De raptos, violaciones y otras inconveniencias}

El rapto fue corregido con respecto a su publicación original al incluirse en la colección $D e$ raptos, violaciones y otras inconveniencias, donde se pueden apreciar algunos cambios de estilo y la corrección de erratas. Al comienzo de la narración ya hallamos el primer cambio: la secuencia "de esto hace ya años. Debió de ser en el 57 ó 58, hacia la primavera" (Ayala, 1965a: 21) será sustituida en su segunda edición por "de esto hace ya tiempo. Era del año la estación florida" (27). Con tal modificación Ayala traza una conexión con las Soledades de Góngora. Además, el cambio del nombre de Manolo Tejera por Patricio traza otra conexión con la Égloga I de Garcilaso, pues este nombre se asemeja más a Salicio, del mismo modo que Fructuoso evoca a Nemoroso. Con respecto al primer cambio en relación a la coordenada temporal, Durán (1977) aduce que sirve para poner de relieve la presentación de una situación arquetípica, que responde a una constante literaria, lo cual relaciona el crítico con el mito del eterno retorno, en el sentido de que el pasado se repite en el presente. Ya desde el prólogo que acompaña a El rapto y que ahora encabeza esta recopilación ${ }^{5}$ se acentúa el tema del tiempo, presente en diferentes vertientes en todos los relatos: el paso del tiempo para dos ancianos que se conocieron en su juventud en "El as de Bastos", el presente como repetición del pasado en "Violación en California", así como la contemporaneidad en que se desarrollan las historias de "Una boda sonada", "Un pez" y todas las anteriores. Por ello, podemos afirmar que el prólogo de El rapto funciona como prólogo de toda la recopilación, dado que traza conexiones temáticas con todas las narraciones aquí reunidas.

En el relato de asuntos contemporáneos y decisivos para los personajes coinciden la novela corta y el cuento para Maxime Chevalier (1999: 21-22); por ello para este autor es difícil trazar una línea divisoria clara entre estos dos géneros. Los criterios que propone para

\footnotetext{
${ }^{5}$ Aquí este es denominado "prólogo", mientras que en la primera edición de El rapto carecía de tal título.

${ }^{6}$ Son sintomáticas las palabras que cierran el relato: "no hay nada nuevo bajo el sol de California" (1966: 145).
} 
diferenciar una novela corta de un cuento son la mayor complejidad en su configuración estructural, una mayor cantidad de personajes, duración más extensa o la inclusión del pasado de los personajes para darle mayor densidad a su caracterización. Tales premisas las cumple El rapto, pero el resto de narraciones de esta colección se pueden calificar de cuentos. Esta hibridez genérica es propia de las recopilaciones de Ayala, que suele reunir en un mismo volumen textos de distinta naturaleza genérica.

Si bien El rapto es la única obra que evidencia una fuerte huella cervantina, el resto de narraciones también se relacionan intertextualmente con obras clásicas. "El as de Bastos" incluye antes del inicio de la narración cinco citas procedentes de Ovidio, Garcilaso, Shakespeare, Ronsard y Quevedo. Todas ellas aluden al tópico collige, virgo, rosas, en torno al cual gira la trama de este cuento. "Violación en California" no contiene numerosas alusiones literarias como las anteriores narraciones, pero sí muestra una profunda huella cervantina al presentar un personaje que cuenta una historia narrada previamente por otro, por lo que se relaciona con el narrador del Quijote (recuérdese la figura de Cide Hamete Benengeli). En "Una boda sonada", como uno de los protagonistas lleva por nombre Homero, se alude a este poeta griego y su obra la Ilíada; en este relato también podemos hallar una alusión a la Divina Comedia de Dante. Sin embargo, "Un pez”, el cuento que cierra esta colección, no destaca por sus relaciones intertextuales como las narraciones anteriores.

Sin duda, este último cuento llama la atención por su singularidad, dado que es el único texto con narrador homodiegético que utiliza la primera persona. El protagonista de esta historia va a narrar desde el presente lo que le ocurrió un domingo por la tarde. Este personaje hace alarde de su capacidad para ser el único capaz de narrar esta historia, por ello no duda en afirmar en varias ocasiones "solo yo lo sé" (1966: 184). También decide omitir algunos detalles: "lo que me gritó la Gorda fueron cosas que no voy a repetir" (1966: 185) y utiliza el estilo directo para reproducir entrecomilladas las palabras de otros personajes. De ese modo, en este cuento no vamos a hallar diálogos, elemento importante - incluso decisivo- para otras narraciones, donde el narrador es siempre heterodiegético. El narrador omnisciente de "Una boda sonada" dirige toda la narración e incluirá las palabras que los personajes utilizan en determinados momentos en estilo directo con comillas, como en el cuento anterior. En cierta ocasión, incluso hace uso del estilo indirecto libre, haciendo suyas las palabras de Flor Monte: “¿qué se creían, los mamarrachos? ¿Que iban a poder con ella? ¿A que no se aguardaban esa respuesta?" (1966: 166). En El rapto, en cambio, al ser una novela corta, el narrador incluye numerosos diálogos entre distintos personajes, así como un monólogo de Julita tras ser abandonada por Vicente. Cabe destacar que el narrador omnisciente de esta obra ofrece las distintas perspectivas de los personajes, salvo la de Vicente, de quien únicamente conocemos sus pensamientos a través de la carta redactada por él mismo que sirve de epílogo a la novela corta, por lo que podemos afirmar que, en relación a este personaje (protagonista), el narrador ha renunciado a su omnisciencia.

A pesar de que el narrador de "El as de Bastos" sea también omnisciente, este no dirige la narración, sino que será el diálogo entre Bastos y Matilde lo que configure la estructura del relato y permita mayoritariamente el avance de la trama, pues son ellos quienes desde el presente evocan el pasado, y el narrador se limita en general a comentar sus palabras y reacciones. Tal conversación tiene lugar en un viaje en tren, motivo que implica una transformación espacio-temporal. Cuando esta pareja llegue al balneario al que se dirigían, 
será el narrador quien tome las riendas de la narración, si bien los personajes no dejan de conversar. Tanto Bastos como Matilde son personajes que, dentro de un cuento dirigido por un narrador heterodiegético, narran su propia historia, la cual queda enmarcada en ese diálogo que funciona como marco interno: "el marco existe, pero se ha internalizado, está dentro de la historia, no es, digamos, aquello que está antes de que el relato propiamente dicho empiece, sino que está incorporado como un elemento interno de la historia" (Piglia, 2006: 201).

En cuanto a "Violación en California", aquí volvemos a hallar un diálogo entre dos personajes supeditado a la omnisciencia del narrador del cuento. No obstante, estos personajes no van a relatar algo sucedido a ellos mismos, como Bastos, Matilde o el polaco, sino que van a narrar algo ocurrido a otros personajes. El teniente de policía E. A. Harter le va a relatar a Mabel, su esposa, lo que previamente ya había narrado un hombre sobre la violación que había sufrido por parte de dos mujeres; en su narración va a incluir sus propios comentarios sobre tal suceso. A este relato responde Mabel con otro similar que ella recuerda sobre un deficiente mental supuestamente asesinado por dos hermanas que se habían estado aprovechando de él. Estas narraciones supeditadas al diálogo-dependiente, a su vez, de la voz del narrador heterodiegético - constituyen la estructura completa del cuento, mientras que dentro de la trama de El rapto, Vicente y Patricio se convierten en narradores de dos sucesos también similares entre sí. Adrián García Montoro (1968) llamó la atención sobre esta mise en abyme y calificó este tipo de argumentos incluidos en "Violación en California" y El rapto de "fait divers", lo cual fue comentado por el propio Ayala en su ensayo "Reflexiones sobre la estructura narrativa" (2007b).

Si nos fijamos en las técnicas para la elaboración del íncipit y el final de estos relatos, elementos puestos de relieve por László Scholz (2012) para la novela corta, hallamos notables diferencias entre los mismos. En el comienzo de El rapto, el narrador presenta la llegada de Vicente en moto al bar de Anacleto, pero para finalizar la historia no se utiliza la voz narrativa, sino una carta redactada por el propio Vicente que sirve de epílogo, sobre la cual conversarán Patricio y Fructuoso, dejando el final abierto. También en "Una boda sonada" el protagonista es presentado al comienzo por el narrador, quien dirige la trama de forma lineal, si bien adelanta un momento decisivo a modo de prolepsis. Hasta el final del relato será el narrador quien dirija la narración de hechos y finalizará la historia detallando cómo han acabado los protagonistas. Tanto "El as de Bastos" como "Violación en California" empiezan con el diálogo de sus protagonistas. En el primero, se produce el encuentro entre Bastos y Matilde en el tren, donde conversan hasta llegar a su destino. Será en el balneario, lugar en el que acaban, donde el narrador relate lo ocurrido entre los protagonistas, si bien no renuncia a seguir incluyendo las palabras que estos intercambian. "Violación en California" comienza con las palabras de uno de los personajes:

- Lo que es en esta dichosa profesión mía — dijo a su mujer en llegando a casa el teniente de policía E. A. Harter- nunca termina uno, la verdad sea dicha, de ver cosas nuevas. A cuyo exordio, ya ella sabía muy bien que había de seguir el relato, demorado, lleno de circunloquios y plagado de detalles, del caso correspondiente. (1966: 129)

Baquero Goyanes destaca este preámbulo del cuento de tipo tradicional y señala que "concluida tal historia y cuando cabría sospechar que el cuento ha llegado ya a su fin, Ayala introduce una especie de coda" (1977: 317), es decir, el relato que cuenta Mabel sobre un 
suceso similar. Los esposos dan cierre al cuento conversando entre ellos. En cuanto a "Un pez", el narrador homodiegético introduce las palabras que todos le profieren a modo de burla: “«Polaco, ¿no quieres un pez?»” (1966: 177). Este comienza desde el presente narrando lo que le ocurrió y finaliza en el momento presente, cuando aún no se han olvidado del suceso y se siguen burlando de él, por lo que el cuento presenta una estructura circular.

En cuanto al argumento que desarrollan estas narraciones, todas presentan una situación más o menos verosímil y contemporánea, lo cual es propio de la novela corta (Chevalier, 1999). Los personajes tampoco son héroes, sino mundanos; algunos de ellos son seductores, aspecto destacado por Ioana Gruia (2011), como Vicente, Homero y el polaco, protagonistas de El rapto, "Una boda sonada" y "Un pez", respectivamente. En algunos relatos se hace referencia a momentos históricos, como la Guerra Civil en El rapto, la guerra del Pacífico en "Violación en California" y la presidencia de Kennedy en "Un pez". En El rapto asistiremos al desengaño amoroso que sufre Patricio por culpa de su amigo Vicente, que se llevará consigo a su amada para demostrarle que las mujeres no merecen la pena. Por ello, el título de esta novela corta responde a la perspectiva de Vicente, que en su carta indica que ha perpetuado un rapto, si bien Julita se fue con él por decisión propia. "El as de Bastos" relata el encuentro de dos ancianos en un tren que perdieron la oportunidad de estar juntos cuando eran jóvenes y ahora la intimación resulta decepcionante y frustrante. Cabe resaltar que el título alude a cómo Matilde denomina al pene de su amante cuando van a mantener relaciones sexuales: "Es el As de Bastos. Yo siempre lo llamaba así, cuando me lo representaba en mis fantasías: el As de Bastos. Una adaptación del chistecito de Julio, para mi uso privado. Nunca pensarías tú, idiota, que yo no pensaba sino en este dichoso As de Bastos. Ahora, por fin, ya lo tengo en la mano, y no lo suelto. ¿Sabes que no lo suelto?” (1966: 125).

"Violación en California" hace alusión ya desde el título al argumento que desarrolla: una violación perpetuada por dos mujeres a un hombre que intentó ayudarlas en la carretera. Harter, al relatar este hecho, hace hincapié en la necesidad que tenían las mujeres de realizar el acto con violencia, pues la víctima les aseguró que las complacería gustosamente, pero ellas se negaron a no usar una pistola amenazante durante el acto. El relato similar que le cuenta Mabel es sobre dos hermanas que se aprovechaban de un deficiente mental para explorar su cuerpo. Como este apareció muerto por haber ingerido comida con cristales, Mabel cree que lo asesinaron las hermanas para evitar que las delatara. "Una boda sonada" ofrece una historia de amor que acaba en matrimonio entre los protagonistas. Ahora bien, el sentimiento amoroso surgió cuando Flor halló consuelo en Homero tras haber hecho algo obsceno en el escenario como respuesta a los ultrajes del público: "levantó la pierna y disparó contra ellos explosiva detonación: como el diablo en la Divina Comedia, avea del cul fatto trombetta" (1966: 162). La clave del título es la palabra "sonada", pues este matrimonio es una muestra de orgullo ante todos aquellos que se habían burlado de los protagonistas. En cuanto a "Un pez", este cuento esboza, en palabras de Ángel García Galiano, "la crisis existencial que puede provocar la irrupción de un hecho inopinado en una vida muelle y programada para la indolencia abúlica" (1994: 126), por lo que ese pez muerto que da título al cuento funciona como metáfora o alegoría, como menciona el propio Ayala (1965b).

Todos los argumentos son, por tanto, realistas y verosímiles, y a ellos suele responder el título de la narración que los contiene, de modo que tal paratexto es de significativa importancia, la cual ya ha sido destacada en el ámbito de la crítica literaria por Martínez 
Arnaldos (2003). A pesar de ese realismo, todas las tramas presentan cierta ambigüedad. En El rapto, los motivos que tiene Vicente para raptar a Julita no están claros, pues él señala que es para demostrarle a Patricio que todas las mujeres son iguales, aunque el lector puede sospechar que esa intención encierra un deseo amoroso hacia su amigo. Matilde en "El as de Bastos", a pesar de haber estado denostando a su marido, susurra su nombre cuando mantiene relaciones con Bastos y acaba llorando. Como lectores podemos preguntarnos si llora porque aún ama a su marido o porque siente que debió acostarse con Bastos cuando eran jóvenes. Las historias de "Violación en California" y "Un pez" no son fiables, pues dependen de un narrador en primera persona; Harter cuenta algo que ha oído narrar a la víctima de una violación $^{7}$ y defiende en todo momento su integridad y buena educación en la comisaría, sobre lo cual podemos desconfiar. Lo mismo sucede con la historia contada por Mabel, de la que, además, no podemos saber si las hermanas asesinaron a su vecino o no. Del mismo modo, el polaco cuenta desde su punto de vista toda la historia. Además, se desconocen los motivos por los que le dejaron un pez enorme muerto en su casa y de dónde procedía este. Por último, "Una boda sonada" ofrece un final desconcertante, dado que durante toda la trama se ha presentado a los protagonistas como artistas por verdadera vocación y, cuando sus oficios de poeta y bailarina no les brindan tanto dinero, abandonan su pasión por trabajos frívolos y más rentables. Podemos concluir, entonces, que se cumple lo que afirma Piglia sobre la novela corta o la nouvelle (y, en nuestro caso, también el cuento moderno): "nunca descifra por completo los enigmas que plantea" (2006: 194). Tal ambigüedad puede entenderse como una característica propia de la retórica ayaliana, que responde, además, en el caso de El rapto, a la influencia cervantina.

De raptos, violaciones y otras inconveniencias reúne, por tanto, textos que desarrollan motivos similares, ya adelantados en el título de la colección: la violencia en diferentes facetas, el sexo y el desengaño amoroso ${ }^{8}$. A todos estos motivos subyace un tema común: la representación de los actos e intenciones más desagradables - y genuinos — del ser humano; actos que, por otra parte, se perpetúan en el tiempo, como comentábamos al mencionar la conexión entre la temática temporal del prólogo y las narraciones. Diferentes críticos y el propio Ayala (1965b) han afirmado que tal desenmascaramiento de las pretensiones humanas es tema literario que el escritor desarrolla en toda su obra. En este caso, aparece revestido con un tono jocoso, irónico, grotesco y "escatológico", como el propio Ayala señala en la introducción a Mis páginas mejores, donde, como respuesta al crítico H. Rodríguez Alcalá, que distinguió el estilo noble y escatológico en la obra del escritor, detalla que se trata de dos técnicas "en busca de una expresión adecuada para transmitir, por vía estética, la intuición de la realidad" (1965b: 13). Además, se lamenta de que este crítico y muchos lectores hayan encontrado sus narraciones escatológicas chocantes y, por tanto, incomprensibles. Ello explica la mala recepción que tuvieron estos relatos. Max Aub le comentaba a Ayala en una carta fechada en 1962 — disponible en la página web de la Fundación Francisco Ayala - que se había divertido mucho leyendo As de Bastos, obra que, por otra parte, le parecía "impublicable". El prólogo que acompañó a la primera edición de esta última colección —que contenía cuatro narraciones incluidas después en De raptos, violaciones y otras

\footnotetext{
${ }^{7}$ Los motivos que llevaron a las agresoras a violar a este hombre también se desconocen.

${ }^{8}$ Incluso en "Un pez", el polaco cuenta cómo tras acostarse con su vecina — siendo infiel a su esposa- la abofeteó por haberlo manchado con la sangre de su menstruación.
} 
inconveniencias - estuvo a cargo de H. A. Murena (1963), quien también puso de relieve la escasa popularidad entre el público lector de la obra ayaliana, debido a que — afirmaba — esta era verdaderamente revolucionaria y el mundo, que hipócritamente deseaba una revolución, no estaba preparado para ella.

\section{Conclusión}

El rapto, obra que destaca por los numerosos trasvases literarios que ha sufrido, quedó incluido en su segunda edición en una recopilación en la que sus narraciones ofrecen numerosos puntos en común: la temática, motivos recurrentes, un tono escatológico, argumentos desarrollados en tiempo presente y narrados en su mayoría por un narrador omnisciente que hace uso especial de los diálogos, así como la ambigüedad y la inclusión de alusiones literarias. Todo ello da cohesión a esta colección, a pesar de que sus textos hubieran sido publicados previamente en otros medios. Tal unidad no es extraña a la creación literaria de Ayala, pues toda su obra narrativa forma parte de un conjunto único, así lo ha afirmado el propio escritor (1965b). Su visión del mundo, dependiente de una "refinada y doliente conciencia cívica" (García Galiano, 1994: 114) y de la intención de interpretar nuestro presente histórico (Ayala, 1966), se puede descifrar en todos sus escritos. Así, El rapto, siendo una recreación de un argumento cervantino, es capaz de reflejar el mundo contemporáneo $\mathrm{y}$, en definitiva, al ser humano, como hacen el resto de cuentos que lo acompañan en De raptos, violaciones y otras inconveniencias.

\section{Bibliografía}

ÁlVAREZ MURENA, Héctor (1963): "Prólogo". En Francisco Ayala, El As de Bastos. Buenos Aires, Sur: 7-11.

AYALA, Francisco (1965a): El rapto. Madrid, Alfaguara (La Novela Popular Contemporánea, inédita, española, $\left.n .^{\circ} 1\right)$.

--- (1965b): Mis páginas mejores. Madrid, Gredos.

--- (1966): De raptos, violaciones y demás inconveniencias. Madrid, Alfaguara.

--- (1993): El rapto. Madrid, Alfaguara.

--- (2007a): "Nueva divagación sobre la novela". En Carolyn Richmond (ed.), Estudios literarios. Obras Completas III. Barcelona, Círculo de Lectores / Galaxia Gutenberg: 163-178. [1967].

--- (2007b): "Reflexiones sobre la estructura narrativa". En Carolyn Richmond(ed.), Estudios literarios. Obras Completas III. Barcelona, Círculo de Lectores / Galaxia Gutenberg: 48-87.

--- (2012): Narrativa. Obras Completas I. Ed. Carolyn Richmond. Barcelona, Círculo de Lectores / Galaxia Gutenberg.

BAQUERO GOYANES, Mariano (1977): “Cervantes y Ayala: el arte del relato breve". Cuadernos Hispanoamericanos 329/330 (1977): 311-326. 
CHEVALIER, Maxime (1999): "Prólogo". En María Jesús Lacarra (ed.), Cuento y novela corta en España I. "Edad Media”. Barcelona, Crítica: 9-24.

DURÁN, Manuel (1977): "Notas sobre Francisco Ayala, «El rapto», y el mito del eterno retorno". Cuadernos Hispanoamericanos 329/330 (1977): 441-448.

FUNDACIÓN FRANCISCO AYALA: www.ffayala.es. [17/09/2018].

GARCÍA GALIANO, Ángel (1994): "La narrativa de Francisco Ayala: teoría y práctica". Dicenda. Cuadernos de filología hispánica 12 (1994): 111-128.

GARCÍA MONTORO, Adrián (1968): “El rapto, novela ejemplar”. La Torre: Revista de la Universidad de Puerto Rico 62 (1968): 151-165.

GRUIA, Ioana (2011): "La seducción del cuento: huellas cervantinas en «El rapto» de Francisco Ayala”. En Luis García Montero y Milena Rodríguez Gutiérrez (eds.), De este mundo y los otros. Estudios sobre Francisco Ayala. Madrid, Visor Libros: 331340.

INGRAM, Forrest L. (1971): Representative Short Story Cycles of the Twentieth Century. París/La Haya, Mouton. DOI: https://doi.org/10.1515/9783110888546

LANGLET, Irène (2003): "Parcours du recueil". En Irène Langlet (ed.), Le Recueil Littéraire, pratiques et théorie d'une forme. Rennes, Presses Universitaires de Rennes: 11-18. DOI: https://doi.org/10.4000/books.pur.32019

MARTÍNEZ ARNALDOS, Manuel (1996): "Deslinde teórico de la novela corta". Monteagudo 3. ' época, 1 (1996): 47-66.

--- (2003): Los títulos literarios. Madrid, Nostrum.

MATELO, Gabriel (2010): "Short Story Cycle/Cuentos integrados: apropiaciones nacionales y continentales de un formato narrativo". En Américo Cristófalo, Jerónimo Ledesma y Karina Bonifatti (eds.), Actas del IV Congreso Internacional de Letras. Buenos Aires, UBA: 2207-2212.

MORA, Gabriela (1993): "Notas teóricas en torno a las colecciones de cuentos cíclicos o integrados". Revista Chilena de Literatura 42 (1993): 131-137.

NOGUEROL, Francisca (2008): “Juntos, pero no revueltos: la colección de cuentos integrados en las literaturas hispánicas”. En Vicente Cervera Salinas y M. ${ }^{a}$ Dolores Adsuar (eds.), Alma América (in honorem Victorino Polo). Murcia, Universidad de Murcia: 162-172.

PIGLIA, Ricardo (2006): "Secreto y narración. Tesis sobre la nouvelle". En Eduardo Becerra(ed.), El arquero inmóvil. Nuevas poéticas sobre el cuento. Madrid, Páginas de Espuma: 187-205.

PUJANTE SEGURA, Carmen M." (2018): "Francisco Ayala, escritor de novelas cortas: recontextualización y revalorización de El rapto". Lejana 11 (2018): 70-82. DOI: https://doi.org/10.24029/lejana.2018.11.257

RICHMOND, Carolyn (2011): "Raíces de la (re)creación: reflejos del exilio en Los usurpadores". En Luis García Montero y Milena Rodríguez Gutiérrez (eds.), De este mundo y los otros. Estudios sobre Francisco Ayala. Madrid. Visor: 15-40.

RIVALAN GUÉGO, Christine y Miriam NICOLI (2014): “Introduction”. En Christine Rivalan Guégo y Miriam Nicoli (dir.), La Collection. Essor et affirmation d'un objet 
éditorial (Europe/Amériques XVIII ${ }^{e}-X X I^{e}$ ). Rennes, Presses Universitaires de Rennes: 9-15. DOI: https://doi.org/10.4000/books.pur.54783

RUEDA, Ana (1995): "Los perímetros del cuento hispanoamericano actual". En Enrique Puppo Walker (ed.), El cuento hispanoamericano. Madrid, Castalia: 551-571.

SÁNCHEZ CARBÓ, José (2012): “Colecciones ejemplares. Los relatos integrados de Enrique Vila-Matas”. En Felipe A. Ríos Baeza (ed.), Enrique Vila-Matas. Los espejos de la ficción. México, Benemérita Universidad Autónoma de Puebla / Ediciones Eón: 115130.

SCHOLZ, László (2013): “La novela corta, ¿un género entre la novela y el cuento?” En Heriberto Cairo Cairou et al. (eds.), Actas Congreso Internacional América Latina: La autonomía de una región. XV Encuentro de Latinoamericanistas Españoles (Noviembre 2012). Madrid, Trama Editorial / CEEIB:1073-1079.

VAUTHIER, Bénédicte (2017): "Las teorías sobre los «ciclos de cuentos integrados»a prueba de cuatro cuentarios sobre la «Destrucción del idilio de la tierra natal» de Juan Eduardo Zúñiga (Largo noviembre de Madrid, La tierra será un paraíso, Capital de la gloria y La trilogía de la Guerra Civil)”. Hispanófila 179 (2017): 41-59. DOI: https://doi.org/10.1353/hsf.2017.0005

(C) Sandra Mendoza Vera

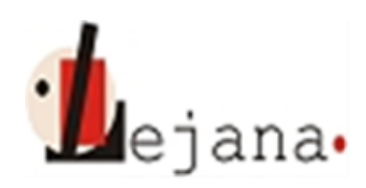

http://ojs.elte.hu/index.php/lejana

Universidad Eötvös Loránd, Departamento de Español, 1088 Budapest, Múzeum krt. 4/C 